\title{
Exploring new structures for the development of CPL-dyes based on flexible bis(BODIPY)s
}

\author{
César Ray, ${ }^{a}$ Antonio J. Gómez-Infante, ${ }^{\mathrm{b}}$ Antonia R. Agarrabeitia, ${ }^{\mathrm{a}}$ Florencio Moreno, ${ }^{\mathrm{a}}$ Beatriz L. Maroto, ${ }^{\mathrm{a}}$ \\ María J. Ortiz, ${ }^{a}$ Eduardo Peña-Cabrera, ${ }^{b}$ Santiago de la Moya ${ }^{a}$ \\ ${ }^{a}$ Departamento de Química Orgánica I. Facultad de Ciencias Químicas. Universidad Complutense de Madrid. Ciudad \\ Universitaria s/n, 28040 Madrid, Spain.

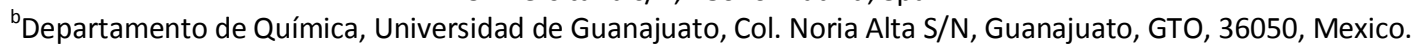 \\ E-mail: santmoya@ucm.es, belora@ucm.es
}

\begin{abstract}
Circularly polarized luminescence $(C P L)$ is a chiroptical phenomenon consisting of the differential emission of right and left circularly polarized light by chiral systems (such as molecules, ionic pairs, polymers, metal complexes, supramolecular aggregates). The interest of CPL is due to the resolution provided by the circular polarization of the light, which allows the development of smarter photonic materials for useful technologies, such as 3D displaying, information storage and processing, communication of spin information (spintronics), or bioimaging (for example, ellipsometry-based tomography).

In our Group, we have demonstrated that conformationally flexible bis(BODIPY)s are a good platform for the development of smart CPL-SOMs (single organic molecules enabling $\mathrm{CPL}$ ). We present in this communication synthetic strategies for the modification of the parent structure, directed to the optimization of the CPL properties: (1) Introduce sterical hindrance in the flexible bridge, in order to modify the dihedral angle in the induced helix and (2) Explore new positions at which the bridge connecting both chromofores can be attached.
\end{abstract}
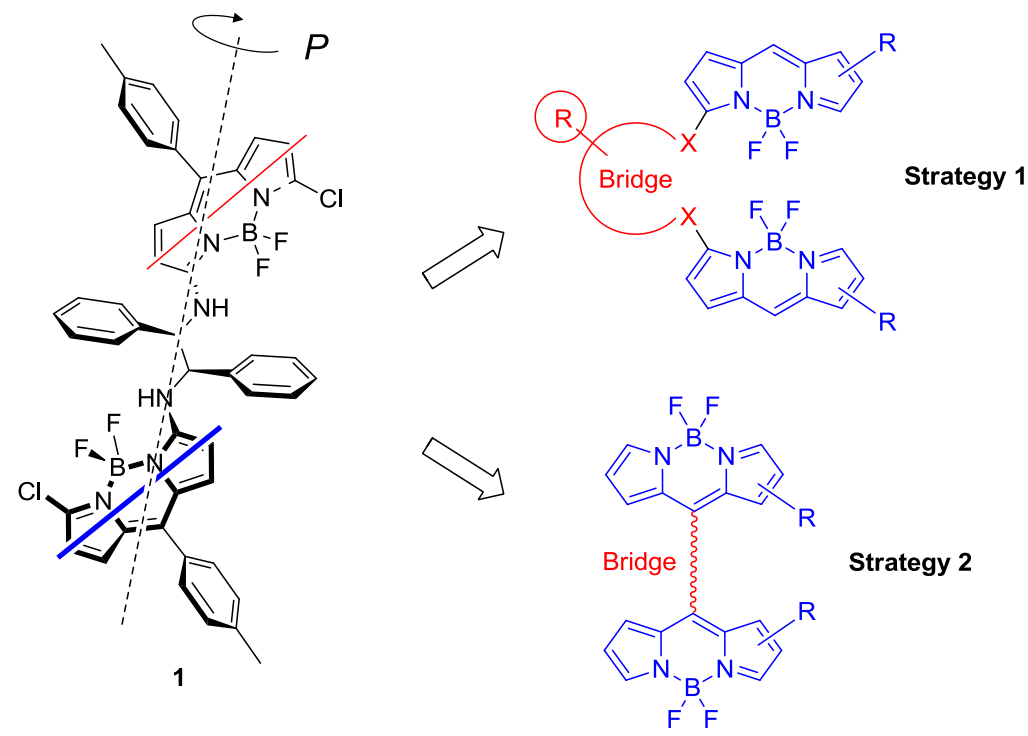


\section{INTRODUCTION}

Circularly polarized luminescence $(C P L)$ is a chiroptical phenomenon that entails the differential emission of right and left circularly polarized lights by chiral systems (molecules, ionic pairs, polymers, metal complexes, supramolecular aggregates, etc.). ${ }^{[1]}$ The interest of CPL is due to the resolution provided by the circular polarization of the light, which allows the development of smarter photonic materials for useful technologies, such as 3D displaying, ${ }^{[2]}$ information storage and processing, ${ }^{[3]}$ including high-security chiroptical cryptography, ${ }^{[3 c]}$ communication of spin information (spintronics-based devices), ${ }^{[4]}$ or bioimaging (e.g, ellipsometry-based tomography). ${ }^{[5]}$ Moreover, circularly polarized light can be used to promote asymmetric photochemistry, ${ }^{[6]}$ to control the morphology in nanomaterials, ${ }^{[7]}$ or to detect chiral environments (chiral sensing). ${ }^{[8]}$ All these characteristics make CPL valuable for the development of envisaged advanced photonic technologies (e.g., CPL microscopy). ${ }^{[9]}$ Besides, but not less important, spectroscopy based on CPL is an indispensable source of information to know chirality factors in luminescent excited states. ${ }^{[1 b, 10]}$

The level of CPL is quantified by the luminescence dissymmetry factor, $g_{\text {lum, }}{ }^{[1 \mathrm{~b}, 11]}$ whose values stand between -2 and +2 (completely right and left circularly polarized emission, respectively). Among the well-established chiral systems enabling CPL, mainly photoluminescent chiral lanthanide complexes with $\left|g_{\text {lum }}\right|$ values typically into the 0.05-0.5 range, ${ }^{[1 d, e, 9 a, 10 c, 12]}$ those based on simple (small, non-polymeric and non-aggregated) organic molecules, CPL-SOMs, have attracted considerable attention during the last five years. ${ }^{[13,14]}$ This is due to the enormous technological potential of these molecules to develop future advanced photonic (chiroptical) materials, mainly due to properties associated to the small size, which makes them interesting for the development of physiological CPL applications, as well as to their excellent organic-solvent solubility, which makes them valuable for the development of CPL-active dye-doped inclusion materials. $^{[13 a]}$

Helicity has been demonstrated to be a privileged structural motive to achieve CPL in SOMs. ${ }^{[13 a]}$ In this sense, significant $g_{\text {lum }}$ values have been reported for several CPL-SOMs 
having helical chirality (mainly helicenes). ${ }^{[13 a, 14]}$ However, with the exception of scarce cases (helicene-like molecules), ${ }^{[14 b]}$ the distortion of the involved helicene chromophore, which is associated to the enhanced CPL activity, usually spoils the emission efficiency at the same time. ${ }^{[13 a]}$ Furthermore, the enantiopure preparation of these CPL-SOMs is not straightforward in most cases. ${ }^{[13 a, 14]}$

Hence, CPL-SOMs are rare, exhibit very small levels of circular polarization $\left(\left|g_{\text {lum }}\right|\right.$ typically into the $10^{-5}-10^{-3}$ range), and are restricted to a small number of chiral designs, which usually demand highly inefficient synthetic routes (racemate resolution or complex asymmetric processes are typically involved). ${ }^{[13 a]}$ Additionally, in most cases, the best $g_{\text {lum }}$ values are not coincident with the best emission efficiencies, or with the easiest synthetic procedures. ${ }^{[13]}$ Therefore, new structural designs for CPL-SOMs, combining together CPL activity, emission efficiency and synthetic accessibility (allowing future cost-effective materials) are required.

Regarding helicity and easily accessible SOMs, we have previously reported the capacity of $(\boldsymbol{R}, \boldsymbol{R})-\mathbf{1}$ and $(\boldsymbol{S}, \boldsymbol{S})-\mathbf{1}$ to adopt a self-induced preferential helical conformation in chloroform solution ( $P$ for the former, $M$ for the latter; see Figure 1 ), leading to a strong and clearly bisignated visible (Vis) circular dichroism, which is due to the chirallyperturbed exciton-coupled absorption of the involved identical BODIPY (4,4-difluoro-4bora-3a,4a-diaza-s-indacene) chromophores. ${ }^{[15]}$ It must be noted here that, despite of the recognized importance of the BODIPY dyes in photonics, the study of chirality features in BODIPYs is still scarce, ${ }^{[13 a, 15-17]}$ and chirally-perturbed BODIPY chromophores enabling CPL unusual. $^{[13 a, 17]}$ This chiroptical behaviour of $(\boldsymbol{R}, \boldsymbol{R}) \mathbf{- 1}$ and $(\boldsymbol{S}, \boldsymbol{S}) \mathbf{- 1}$ at their ground state, joined to their helical character and synthetic accessibility, prompted us to investigate their capacity to enable CPL. We found a CPL activity in the range of other CPL-SOMs. In this way, we established helically labile bis(haloBODIPYs) as an advantageous platform for the development of CPL-SOMs. This new design comprises, all-in-one, synthetic accessibility, labile helicity, possibility of reversing the handedness of the circularly polarized emission and reactive functional groups. All these characteristics make the new design unique and attractive as an advantageous platform for the development of smart CPL-SOMs. ${ }^{[18]}$ 


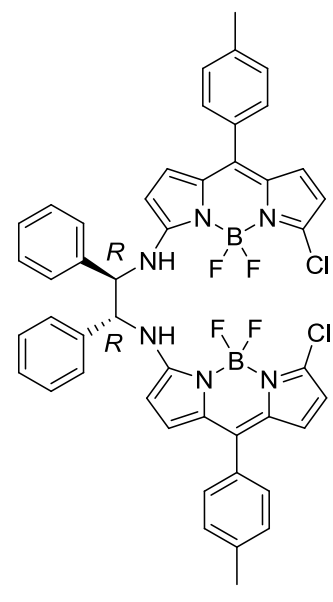

$(R, R)-1$

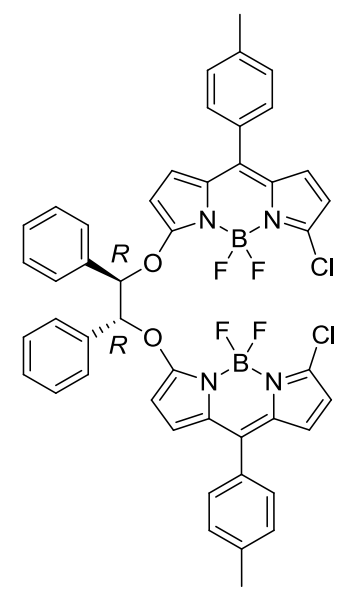

$(R, R)-2$

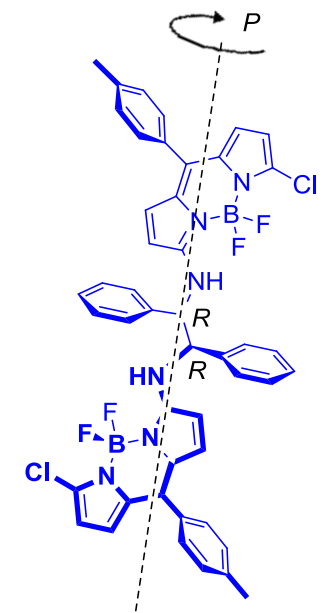

Configurational-labile

Figure 1. CPL-SOMs reported by us (only the $R, R$ enantiomers are shown), and known preferential helical conformation for $(\boldsymbol{R}, \boldsymbol{R})-\mathbf{1}$ (in blue).

Additionally, we have described a change in the CPL sign with a small structural change in the bridge (nitrogen by oxygen, see $\mathbf{2}$ vs. 1 in Figure 1). The found CPL reversal is very interesting, since the establishment of ways for the modulation of the circular handedness, by structural changes different to the inversion of the absolute stereochemical configuration, is a hot research objective in CPL-SOMs. ${ }^{[13 d, 19]}$ Moreover, this CPL reversal demonstrates that small changes in the structure of the chiral bridge can affect enormously the CPL emission.

Based on our previous work, we are now interested in exploring synthetic strategies for the structural modification of the parent structure (1), directed to the optimization of the CPL properties of these dyes. Our first strategy lies in introducing large substituents in the flexible bridge, that would modify the dihedral angle in the induced helix. This change in the helicity is expected to have an effect on the chiroptical properties of the dye, since the latter are a consequence of the former. The second strategy is to explore new positions at which the chiral bridge connecting both chromophores can be attached, particularly, the meso position. This change would lead to a new structure which we expect would adopt a helical conformation as well, originated by the chiral bridge, analogously to what we 
found for 1 . This new structure could present a new behavior, regarding its chiroptical properties.

\section{RESULTS}

\section{Strategy 1: Steric effects in the chiral bridge}

A series of bis(haloBODIPYs) based on 1 was synthesized (3-9, Figure 3). Commercially available chiral diamines $\mathbf{1 0}$ were chosen for this purpose, in order to have simple syntheses. Amines $\mathbf{1 0 a - c}$ have different sterically-demanding substituents, while keeping the structure of the chiral bridge in parent structure $\mathbf{1}$. Additionally, compounds 6-9, ${ }^{[21]}$ having a more conformationally restricted bridge, were introduced here to complete the series.

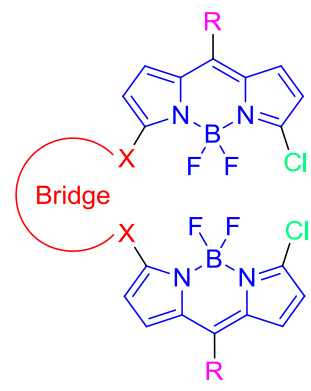

3: $\mathrm{R}=p$-tolyl; Bridge $=\mathrm{a}$

4: $\mathrm{R}=p$-tolyl; Brigde $=\mathrm{b}$

5: $\mathrm{R}=p$-tolyl; Brigde $=\mathrm{c}$

6: $\mathrm{R}=p$-tolyl; Bridge $=\mathrm{d}$

7: $R=$ mesityl; Bridge $=d$

8: $\mathrm{R}=\mathrm{CF}_{3} ;$ Bridge $=\mathrm{d}$

9: $\mathrm{R}=p$-tolyl; Bridge $=\mathrm{e}$
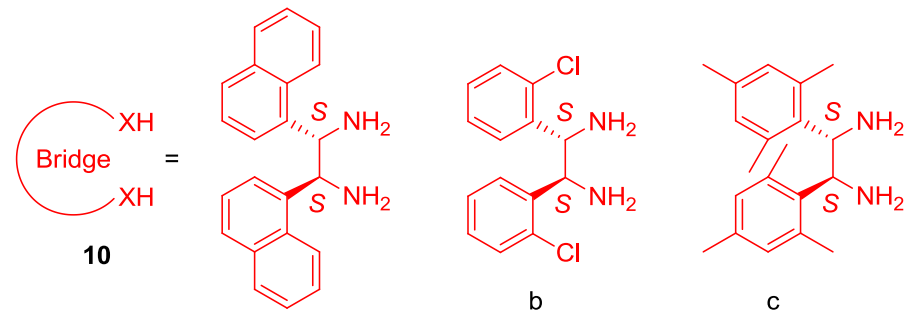

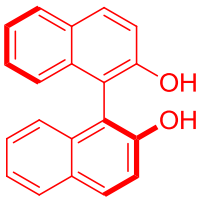

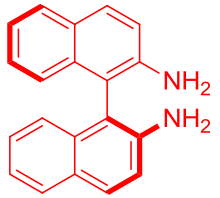

a

Figure 3. Series of bis(haloBODIPYs) with structural modifications in the flexible bridge synthesized in this work and in ref. [21].

The synthesis of 3-5 was attempted starting from accessible meso-( $p$-tolyl)- $\alpha, \alpha^{\prime}-$ dichloroBODIPY (11), ${ }^{[22]}$ using the corresponding enantiopure diamine $10 a-c$, according to the procedure used for the synthesis of $\mathbf{1}^{7 a}$. However, the lower reactivity of these amines when compared to 1,2-diphenylethan-1,2-diamine made necessary to find new reaction conditions. After different attempts, 3-5 could be obtained by changing the base from $\mathrm{Et}_{3} \mathrm{~N}$ to the less nucleophilic $\mathrm{Et}^{i} \operatorname{Pr}_{2} \mathrm{~N}$. 


\section{Strategy 2: New positions for the connection of the chromophores}

For the preparation of bis(BODIPYs) connected through the meso position 12-16 (see Figure 3), 8-methylthioBODIPY (17) ${ }^{[23]}$ was used as the starting material. First, bis(BODIPY) 12, having the same spacer as analogous 1, was prepared by an optimized synthetic procedure based on the previously reported by Peña-Cabrera for $S_{N} A r$ at meso position, ${ }^{[24],[25]}$ that is, the reaction of 17 with $(1 R, 2 R)$-1,2-diphenylethane-1,2-diamine in the presence of DMAP in refluxing DCM (see Scheme 1). Even with these optimized conditions for obtaining 12, the major product was always monoBODIPY 18. Then, 13 (analogue of 2) could be obtained from 17 and (1R,2R)-1,2-diphenylethane-1,2-diol, by copper catalyzed $S_{N} A r$, as described by Peña-Cabrera ${ }^{[24],[25]}$ (Scheme 2).

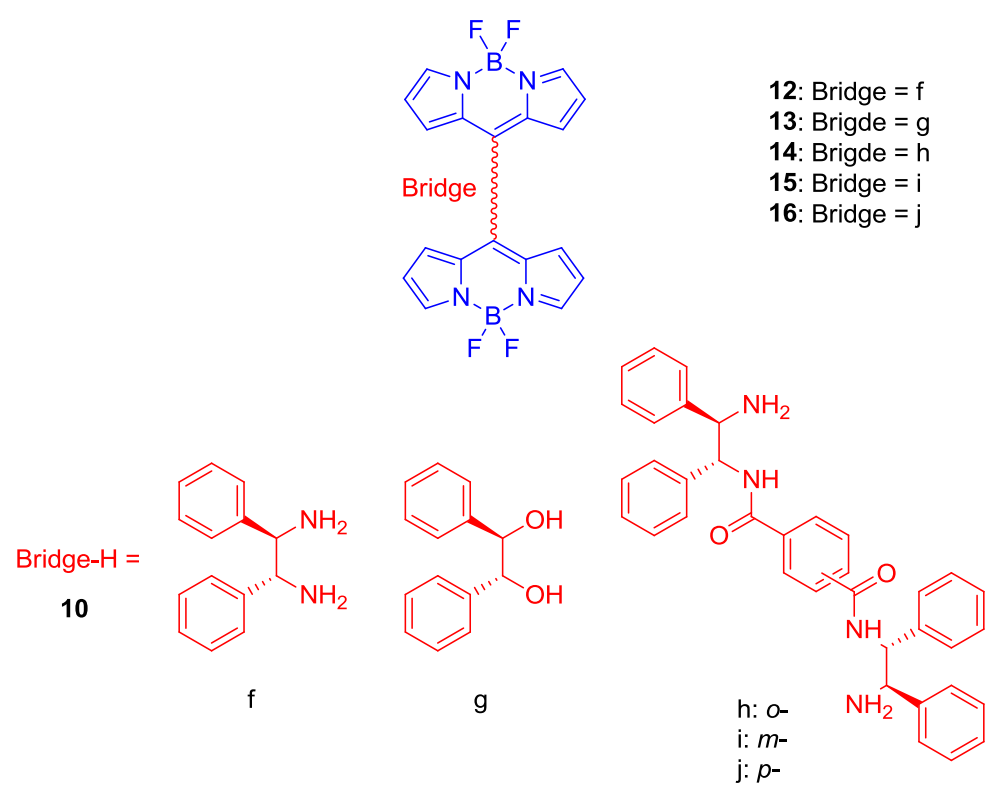

Figure 3. Series of chiral bis(haloBODIPYs) in which the chromophores are connected through the meso position.

The formation of 18 as the major product in the reaction of 17 with $(1 R, 2 R)-1,2$ diphenylethane-1,2-diamine provided us with the possibility of making chiral bis(BODIPYs) with longer spacers. Thus, the coupling of $\mathbf{1 8}$ with each isomer of phthalic acid led to bis(BODIPYs) 14 - 16, as shown in Scheme 3. 


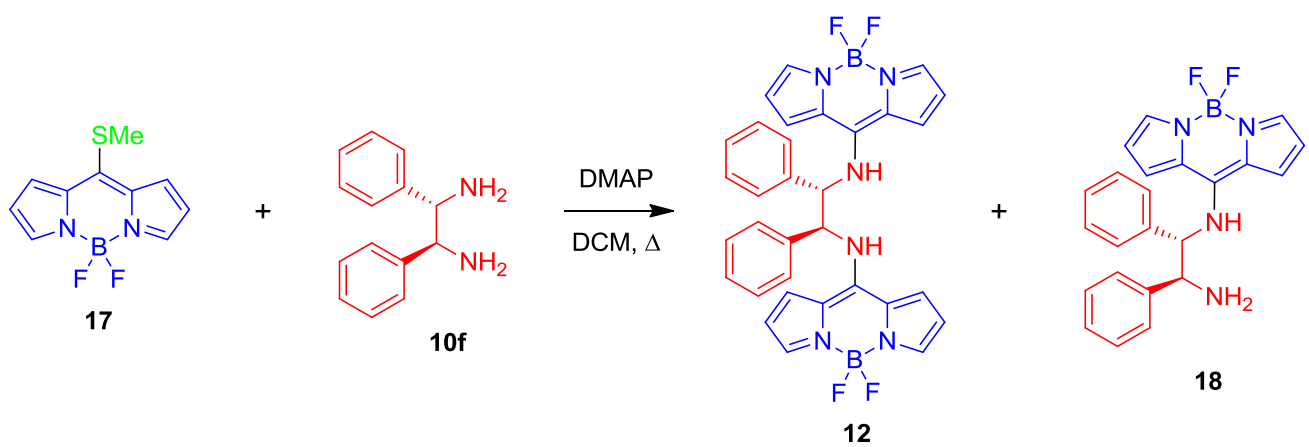

Scheme 1. Synthesis of bis(mesoBODIPYs) having a flexible diamine as the chiral spacer.

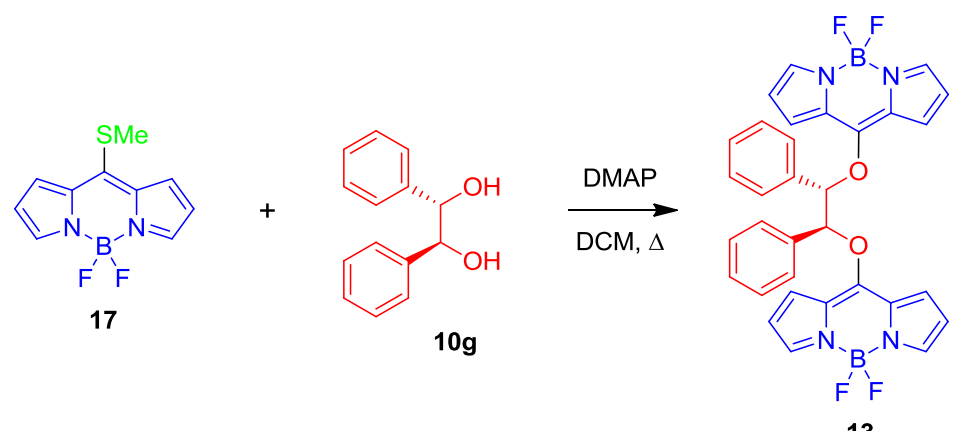

Scheme 2. Synthesis of bis(mesoBODIPYs) having a flexible diol as the chiral spacer.

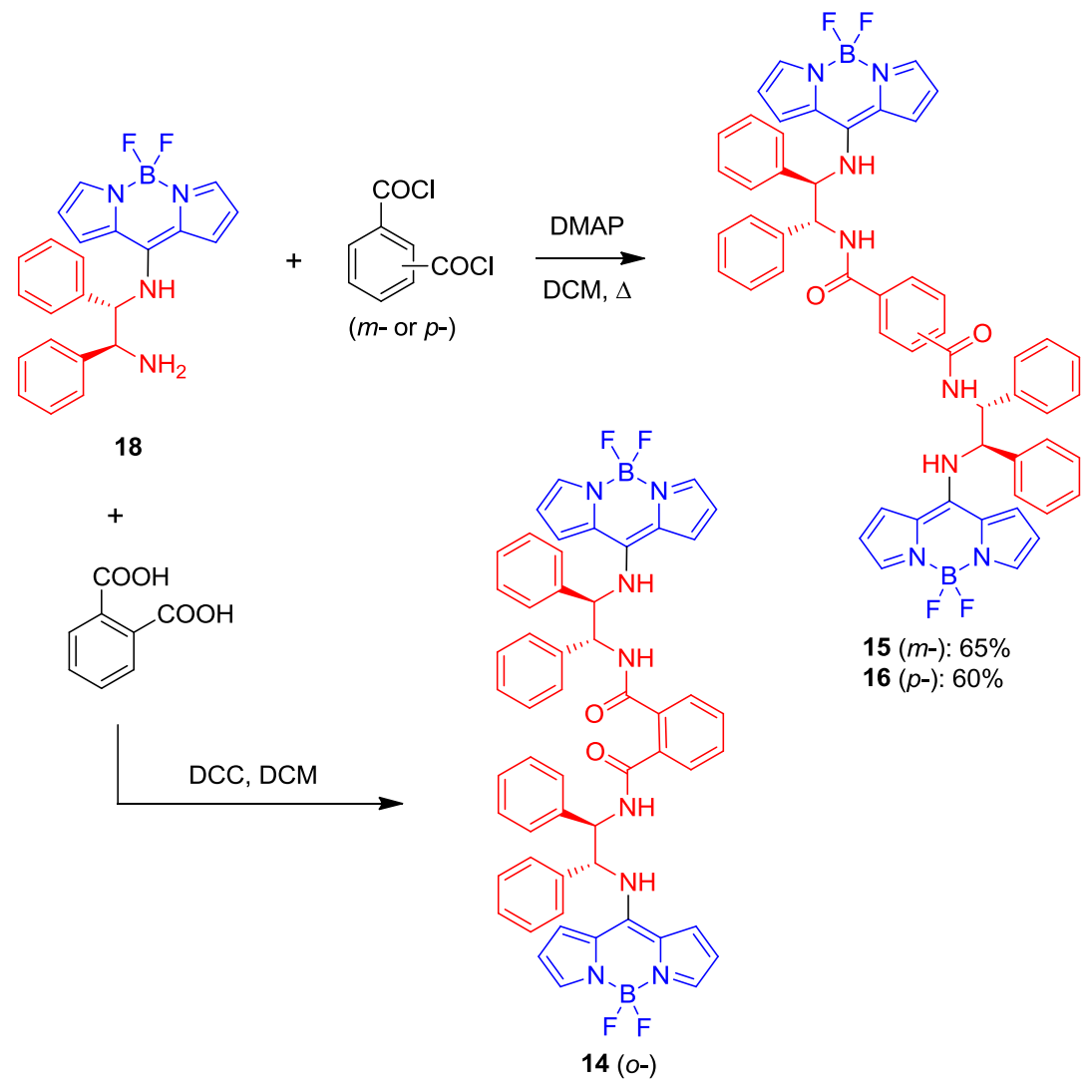

Scheme 3. Synthesis of bis(mesoBODIPYs) having a longer amine spacer. 


\section{CONCLUSION}

We have synthesized two new series of chiral conformationally flexible bis(BODIPYs) by simple, one-step syntheses. In the first one, we have introduced modifications in the chiral bridge (large substituents in the diamine spacer and a binaphtyl unit tethering the two chromophores ${ }^{[21]}$ ). These modifications are expected to alter the dihedral angle of the spacer, changing the induced helix, and having an influence in the CPL of the dyes. These change in the change of CPL based on a change on the structure will provide us with valuable information for the design of new bis(BODIPYs) with optimized CPL properties.

Additionally, we have prepared a second series of bis(BODIPYs) where the BODIPY units are attached by the meso position. We think that these structures can form a conformationally flexible helix in solution, as well, hence opening the way to explore new designs for CPL-SOMs.

\section{ACKNOLEDGEMENTS}

Financial support from Spanish MICINN (MAT2014-51937-C3-2-P) is gratefully acknowledged.

\section{REFERENCES}

[1] a) J. P. Riehl, F. S. Richardson, Chem. Rev. 1986, 86, 1-16; b) H. G. Brittain, Chirality 1996, 8, 357-373; c) Comprehensive Chiroptical Spectroscopy Vol. 1. Instrumentation, Methodologies, and Theoretical Simulations (Eds.: N. Berova, P. L. Polavarapu, K. Nakanishi, R. W. Woody), Wiley, Hoboken, 2012; d) Luminescence of Lanthanide Ions in Coordination Compounds and Nanomaterials (Ed.: A. de Bettencourt-Dias), Wiley, Chichester, 2014; e) F. Zinna and L. Di Bari, Chirality 2015, 27, 1-13.

[2] M. Schadt, Annu. Rev. Mater. Sci. 1997, 27, 305-379.

[3] a) J. F. Sherson, H. Krauter, R. K. Olsson, B. Julsgaard, K. Hammerer, I. Cirac, E. S. Polzik, Nature, 2006, 443, 557-560; b) C. Wagenknecht, C.-M. Li, A. Reingruber, X.-H. Bao, A. Goebel, Y.-A. Chen, Q. Zhang, K. Chen, J.-W. Pan, Nat. Photonics 2010, 4, 549-552; c) T. Amako, K. Nakabayashi, N. Suzuki, S. Guo, N. A. A. Rahim, T. Harada, M. Fujiki, Y. Imai, Chem. Commun. 2015, 51, 8237-8240.

[4] R. Farshchi, M. Ramsteiner, J. Herfort, A. Tahraoui, H. T. Grahn, Appl. Phys. Lett. 2011, 98,162508 (3 pages).

[5] a) C. J. Yu, C. E. Lin, L. P. Yu, C. Chou, Appl. Optics. 2009, 48, 758-764; b) C. M. Jan, Opt. Express 2011, 19, 5431-5441.

[6] a) B. L. Feringa, R. A. van Delden, Angew. Chem. Int. Ed. 1999, 38, 3418-3438; b) I. Sato, R. Yamashima, K. Kadowaki, J. Yamamoto, T. Shibata, K. Soai, Angew. Chem. Int. Ed. 2001, 40, 1096-1098; c) J. Podlech,T. Gehring, Angew. Chem. Int. Ed. 2005, 44, 5776-5777; d) R. M. Pagni and R. N. Compton, Mini-Rev. Org. Chem., 2005, 2, 546-564; e) R. J. Cave, Science, 2009, 323, 1435-1436. 
[7] J. Yeom, B. Yeom, H. Chan, K. W. Smith, S. Dominguez-Medina, J. H. Bahng, G. Zhao, W.-S. Chang, S.-J. Chang, A. Chuvilin, D. Melnikau, A. L. Rogach, P. Zhang, S. Link, P. Král, N. A. Kotov, Nat. Mater. 2014, 14, 66-72.

[8] F. Song, G. Wei, X. Jiang, F. Li, C. Zhu, Y. Cheng, Chem. Commun. 2013, 49, 5772-5774.

[9] a) G. Muller, Dalton Trans. 2009, 9692-9707; b) H. Tsumatori, T. Harada, J. Yuasa, Y. Hasegawa, T. Kawai, Appl. Phys. Express 2011, 4, 011601 (3 pages).

[10] a) J. P. Riehl, G. Muller in Comprehensive Chiroptical Spectroscopy (Eds.: N. Berova, P. L. Polavarapu, K. Nakanishi, R. W. Woody), Wiley, Hoboken, 2012, pp. 65-90, and references therein; b) E. Castiglioni, S. Abbate, F. Lebon, G. Longhi, Methods, Appl. Fluoresc. 2014, 2, 024006 (7 pages); c) G. Muller in Luminescence of Lanthanide lons in Coordination Compounds and Nanomaterials (Ed.: A. de Bettencourt-Dias), Wiley, Chichester, 2014, pp. 77-124.

[11] The level of CPL is usually given by the luminescence dissymmetry ratio, $g_{\text {lum }}(\lambda)=2 \Delta I / I=2\left(I_{L}-I_{R}\right) /\left(I_{L}+I_{R}\right)$, where $I_{L}$ and $I_{R}$ refer, respectively, to the intensity of left and right circularly polarized emissions.

[12] a) M. Seitz, E. G. Moore, A. J. Ingram, G. Muller, K. N. Raymond, J. Am. Chem. Soc. 2007, 129, 1546815470; b) K. Okutani, K. Nozaki, M. Iwamura, Inorg. Chem. 2014, 53, 5527-5537.

[13] a) E. M. Sánchez-Carnerero, A. R. Agarrabeitia, F. Moreno, B. L. Maroto, G. Muller, M. J. Ortiz, S. de la Moya, Chem. Eur. J. 2015, 21, 13488-13500; b) J. Kumar, T. Nakashima, T. Kawai, J. Phys. Chem. Lett. 2015, 6, 3445-3452; c) M. Gon, Y. Morisaki, C. Yoshiki, Eur. J. Org. Chem. 2015, 7756-7762; d) K. Nakabayashi, S. Kitamura, N. Suzuki, S. Guo, M. Fujiki, Y. Imai, Eur. J. Org. Chem. 2016, 64-69; e) M. Gon, Y. Morisaki, R. Sawada, Y. Chujo, Chem. Eur. J. 2016, 22, 2291-2298.

[14] a) H. Sakai, S. Shinto, J. Kumar, Y. Araki, T. Sakanoue, T. Takenobu, T. Wada, T. Kawai, T. Hasobe, J. Phys. Chem. C 2015, 119, 13937-13947; b) R. B. Alnoman, S. Rihn, D. C. O'Connor, A. Black, B. Costello, P. G. Waddell, W. Clegg, R. D. Peacock, W. Herrebout, J. G. Knight, M. J. Hall, Chem. Eur. J. 2016, 22, 9396; c) G. Longhi, E. Castiglioni, C. Villani, R. Sabia, S. Menichetti, C. Viglianisi, F. Devlin, S. Abbate, J. Photochem. Photobiol., A 2016, 331, 138-145.

[15] E. M. Sánchez-Carnerero, F. Moreno, B. L. Maroto, A. R. Agarrabeitia, J. Bañuelos, T. Arbeloa, I. LópezArbeloa, M. J. Ortiz, S. de la Moya, Chem. Commun. 2013, 49, 11641-11643.

[16] a) G. Beer, C. Niederalt, S. Grimme, J. Daub, Angew. Chem. Int. Ed. 2000, 39, 3252-3255; b) G. Beer, K. Rurack, J. Daub, Chem. Commun. 2001, 1138-1139; c) A. Haefele, C. Zedde, P. Retailleau, G. Ulrich, R. Ziessel, Org. Lett. 2010, 12, 1672-1675; d) R. I. Lerrick, T. P. L. Winstanley, K. Haggerty, C. Wills, W. Clegg, R. W. Harrington, P. Bultinck, W. Herrebout, A. C. Benniston, M. J. Hall, Chem. Commun. 2014, 50, 4714-4716; e) T. Bruhn, G. Pescitelli, S. Jurinovich, A. Schaumlöffel, F. Witterauf, J. Ahrens, M. Bröring, G. Bringmann, Angew. Chem. Int. Ed. 2014, 53, 14592-14595.

[17] a) A. Gossauer, F. Fehr, F. Nydegger, H. Stöckli-Evans, J. Am. Chem. Soc. 1997, 119, 1599-1608; b) A. Gossauer, F. Nydegger, T. Kiss, R. Sleziak, H. Stoeckli-Evans, J. Am. Chem. Soc. 2004, 126, 1772-1780; c) S. Kolemen, Y. Cakmak, Z. Kostereli, E. U. Akkaya, Org. Lett. 2014, 16, 660-663; d) X. Ma, E.A. Azeem, X. Liu, Y. Cheng, C. Zhu, J. Mater. Chem. C 2014, 2, 1076-1084; e) S. Zhang, Y. Wang, F. Meng, C. Dai, Y. Cheng, C. Zhu, Chem. Commun. 2015, 51, 9014-9017; f) R. B. Alnoman, S. Rihn, D. C. O'Connor, F. A. Black, B. Costello, P. G. Waddell, W. Clegg, R. D. Peacock, W. Herrebout, J. G. Knight, M. J. Hall, Chem. Eur. J. 2016, 22, 93-96.

[18] C. Ray, E. M. Sánchez-Carnerero, F. Moreno, B. L. Maroto, A. R. Agarrabeitia, M. J. Ortiz, Í. LópezArbeloa, J. Bañuelos, K. D. Cohovi, J. L. Lunkley, G. Muller, S. de la Moya Chem.-Eur. J. 2016, 22, 88058808.

[19] a) J. Kumar, T. Nakashima, H. Tsumatori, M. Mori, M. Naito, T. Kawai, Chem. Eur. J. 2013, 19, 1409014097; b) S. Abbate, G. Longhi, F. Lebon, E. Castiglione, S. Superchi, L. Pisani, L. Fontana, F. Torricelli, T. Coronna, C. Villani, R. Sabia, M. Tommasini, A. Lucotti, D. Mendola, A. Mele, D. A. Lightner, J. Phys. Chem. C 2014, 118, 1682-1695; c) T. Amako, K. Nakabayashi, T. Mori, Y. Inoue, M. Fujiki, Y. Imai, Chem. Commun. 2014, 50, 12836-12839; d) J. Yuasa, H. Ueno, T. Kawai, Chem. Eur. J. 2014, 20, 8621-8627; e) S. Kitamura, K. Nakabayashi, T. Wakabayashi, N. Tajima, M. Fujiki, Y. Imai, RSC Adv. 2015, 5, 6744967453; f) Y. Sheng, D. Shen, W. Zhang, H. Zhang, C. Zhu, Y. Cheng, Chem. Eur. J. 2015, 21, 13196-13200.

[21] C. Ray, J. Bañuelos, T. Arbeloa, B. L Maroto, F. Moreno, A. R. Agarrabeitia, M. J. Ortiz, Í. Lopez-Arbeloa, S. de la Moya, Dalton Trans. 2016, 45, 11839-11848.

[22] T. Rohand, M. Baruah, W. Qin, N. Boens and W. Dehaen, Chem. Commun. 2006, 266. 
[23] T. V. Goud, A. Tutar, J.-F. Biellmann, Tetrahedron 2006, 62, 5084.

[24] C. A. Osorio-Martínez, A. Urías-Benavides, C. F. A. Gómez-Durán, J. Bañuelos, I. Esnal, Í. López Arbeloa, E. Peña-Cabrera, J. Org. Chem. 2012, 77, 5434.

[25] J. O. Flores-Rizo, I. Esnal, C. A. Osorio-Martínez, C. F. A. Gómez-Durán, J. Bañuelos, Í. López Arbeloa, K. H. Pannell, A. J. Metta-Magaña, E. Peña-Cabrera, J. Org. Chem., 2013, 78, 5867. 